Published in Journal of Scholarly Publishing, 37(4) 2006.

\title{
Electronic Publishing in Archaeology
}

\author{
Jingfeng Xia
}

\begin{abstract}
Electronic publishing has currently achieved varying degrees of success in different academic disciplines. This article briefly reviews the exercise of electronic publishing in archaeology and introduces some major efforts in its development. By looking at the challenges and opportunities of these digital projects, the article attempts to pinpoint potential directions of development. An involvement of eprint repositories in supporting archaeological scholarly communication is proposed.
\end{abstract}

\section{Introduction}

Electronic publishing has currently achieved varying degrees of success in different academic disciplines. In archaeology, it has been developing for some time and in several directions. Among current practices of electronic publishing in archaeology, the digital dissemination of research results is relatively scarce. Most efforts have been made to work on preserving and sharing archaeological data. As a result, there are few electronic journals and e-print repositories in this field, but many online databases for archaeological excavations exist. Some museum collections can also be found online.

In general, electronic publishing has not become widely accepted by archaeologists. Information technology is still somewhat marginal to research activities in this respect. This situation could be explained as the result of a 'discipline culture, ${ }^{1}$ because information delivery in archaeology is quite different from that in other academic fields. However, it is obvious that a broad and rapid sharing of information, both at the knowledge level and at the data level, is necessary for archaeological research. It is the responsibility of the creators and managers of digital resources to raise scholars' awareness of the new means of scholarly communication. Specifically, the way electronic publishing is designed and maintained will have a crucial impact on the attitudes of archaeologists toward accepting it.

To better assess the development of electronic publishing in archaeology, it is important to understand what scholars in this field really need for their research. It is also essential to become familiar with how scholars in this field have traditionally circulated scientific data and research results.

\section{What do archaeological researchers need?}

Archaeology is such a broad field that its research methods vary from subject to subject, and various technologies have been applied to different types of research. Some areas in archaeology have incorporated the approaches of related fields, developing into interdisciplinary features. For example, geo-archaeology applies the concepts and methods of earth sciences to archaeological inquiries; ethnoarchaeology employs ethnographic fieldwork observations among living groups as an analogy for understanding peoples of the past; and experimental archaeology studies faunal remains found at archaeological sites. This article, however, will concentrate on mainstream archaeology (i.e., field archaeology), which represents the conventions of archaeological research.

In doing archaeological research, scholars first go into the field to carry out excavations on prehistoric and historic sites. They dig up cultural as well as biological remains from the soil left by people in the past. Archaeological investigations are considered a principal source of knowledge of prehistoric, ancient, and extinct cultures. ${ }^{2}$ In order to reconstruct their history, scholars rely on all the unearthed evidence, such 
as man-made objects, which can be as small as tools and ornaments or as large as architectural residues. The mainstream studies are particularly interested in interpreting man-made objects for their social and cultural significance.

Archaeological data have several characteristics distinctive from those of other fields. The first characteristic is the individualization of material remains. Although molding technology was applied to standardize products in some areas at certain times in the past, most of the objects discovered were produced by human hands. It is not an exaggeration, in most cases, to say that no single object is exactly the same as any other. Scholars have found it difficult to use patterned descriptions to precisely elucidate variations of individual objects. They usually trust their own visual inspections of objects rather than counting on the textual narratives of other scholars about those objects in carrying out their analysis. Second, archaeological data are characterized by their enormous quantity. A typical excavation can yield thousands of pieces of artifacts from one site. Given such massive numbers, neither journal articles nor excavation reports can describe every item from an excavation. Even for the items already covered in a publication, there is often no room to provide full descriptions. It is very common for financial and manpower constraints to prevent such data from further formal publication. A normal practice is for archaeologists to compile a final report to conclude their excavation(s) on a site. The shorter version of such a report may be published as a journal article, while the longer one may not be published at all. Such reports, therefore, will not enter the circulation of data in research activities. Scholars generally become aware of the existence of material discoveries by reading the brief reports or through personal communication. More often than not, they will need to visit particular collections in person in order to visually examine the materials relevant to their own interests. Publications provide less information than is needed.

It is amazing how much energy, time, and money must be invested to bring one item from the soil to publication: discovering it in the soil, measuring its relevance to other objects/features on the site, identifying its geographical stratification, taking it to the lab for clean-up, cataloguing it, repairing it if necessary, drawing and photographing it, and describing it in words. Yet this is only a very simplified version of the cycle. This process has inevitably delayed the availability of data to scholars, to varying extents.

Not only are data processed slowly, but research results are also not easy to get published adequately and promptly. The peer-review process is slow, and the number of scholarly journals is limited. Furthermore, publishers prefer to bring out popular topics that attempt to bridge the gap between professional and lay audiences; pure scientific studies are given lower priority. The obviously ineffective communication situation in the field of archaeology, as described above, has existed for decades. We must bear in mind that archaeology is a huge discipline, with thousands of researchers working in more than 500 academic departments, museums, and other institutions in the United States alone. ${ }^{3}$ Few important universities anywhere in the world are now without archaeology professors and archaeology programs. It should be clear that the communication channels practiced in the field have unfortunately limited its research productivity. What archaeological researchers need are efficient communication platforms that can provide prompt and complete access to excavation materials as well as research results. Electronic publishing is one of the solutions.

\section{How has electronic publishing affected archaeological research?}

As early as the mid-1990s, the importance of electronic publishing to support archaeological research was recognized. Logically, it began with attempts to publish raw data from selected archaeological sites. Data were stored in various digital formats, to be shared with the research community. The earliest digital data were delivered on CD-ROM, but soon the Web became a major vehicle in distributing comprehensive information. 
The United Kingdom was a pioneer in the development of electronic archaeological publications. It still contributes, along with some other European countries, a major portion of the work involved in archiving and disseminating archaeological data. Not only has its research community become actively involved in the campaign for new means of scholarly communication, the British government has also become aware of its importance in promoting research and preservation and has provided the necessary financial support to facilitate related activities. The Archaeology Data Service (ADS) in York is one of the famous organizations that work on handling data preservation and distribution. ${ }^{4}$ Established in 1996, the ADS has endeavored to undertake online data delivery to students and researchers. Through its numerous projects in digital preservation, it has contributed much to the knowledge of archaeologists. Many of its projects are funded by English Heritage, the largest heritage agency in Britain, as well by as other funding agencies.

In the United States, numerous efforts have also been made to create broad and fast ways to circulate archaeological data. The Center for the Study of Architecture/Archaeology (CSA) has been enthusiastic in systems development since 1986. Based at Bryn Mawr College, this center focuses on advancing the use of computer technologies and digital information for architectural history, archaeology, and related disciplines. In addition to the various types of research projects it undertakes, the center publishes quarterly newsletters announcing contemporary developments in digital archiving, both within and outside the centre. ${ }^{5}$

The following sections will briefly review the major developments in electronic publishing in archaeology in both Europe and the United States. Both the achievements and the challenges of these developments are highlighted. The purpose is to illustrate how different types of electronic publishing have helped archaeological research and what are their potentials and problems.

\section{Online Databases Have Been the Standard}

Online databases are considered the standard format for archaeological data sharing. The appearance and rapid improvement of the Web since the mid-1990s have made the creation of online databases possible. The progress of other information technologies adds more value to this method of data sharing. Several projects serve as benchmarks for the development of online databases.

The CSA began to operate the Archaeological Data Archive Project (ADAP) in 1993, working with scholars to bring data sets to the archive. Archaeological databases were placed on the Web, with proper structure to support indexing. The indexes were designed to be machine readable, which, alongside online instructions, made the databases useable. ${ }^{6}$ In the interests of preserving scientific data, the project follows a procedure of making three copies of files on CD-ROM, storing them in separate places, and checking their quality every six months to ensure proper data protection. The project had the initial purpose of making people aware of the problems of data preservation. However, it was not very successful in helping scholars deposit their own digital materials into the data archives. ${ }^{7}$

To encourage normal operation of the project, a pilot project, co-sponsored by the National Center for Preservation Technology and Training, was created to gather the necessary experience, provide technical assistance, and monitor the ADAP process. ${ }^{8}$ This pilot project involved work done under the auspices of State Historic Preservation Offices in California, Colorado, and Pennsylvania, from each of which four projects were selected for participation. A variety of data types were included, such as databases, CAD models, geographic information systems (GIS) data sets, and images.

In Europe, since 2002, the ADS has managed an international project, the ARENA Archives. ${ }^{9}$ Funded by the European Commission to promote awareness of digital preservation among European archaeologists, 
this project brought together a diverse group of experts from Denmark, Iceland, Norway, Poland, and Romania. To serve the needs of different user groups, the project adopted a new model that allows each digital archive to keep its own characteristics. Some of the archives made available excavation materials in the style initiated by ADS: 'They give background and bibliographic information and allow users to download archaeological archives for their own use. ${ }^{10}$ Some key sites were represented in these archives with materials in the form of digital images, data files, field survey records, digital mapping, and plans. Not only did archives vary from each other but individual sites in each archive also had different organizations and presentations. The diversity of the archives made them useful to a wider European audience. Also important to the project were the efforts of its members to enhance its usability by attempting to make it an online research and teaching center.

Almost at the same time, English Heritage supported a series of digital projects. ${ }^{11}$ Rather than archiving paper copies of reports and databases, these projects adopted a hybrid publication strategy. They maintained digital archives from a group of organizations, including the Museum of London Archaeological Service, Albion Archaeology, the Norfolk Archaeological Unit, the Essex County Council Field Archaeological Group, the Oxford Archaeological Unit, and the Cambridge Archaeological Unit. By offering advice and guidance on the digitization of the archives, the projects were able to provide access to both raw and interpreted data sets, allowing users to search and download. English Heritage has collaborated with the ADS to implement the projects that made these data sets available online through the ADS servers.

In addition to these keystone projects, individual research organizations have also created their own online databases to distribute digital materials. Examples include the Digital Archaeological Archive of Chesapeake Slavery in the United States ${ }^{12}$ and the Danebury Project Excavation Digital Archive in England. ${ }^{13}$ A variety of Web portals also exists to collect useful online resources for the subject of archaeology, including archaeology.about.com, ${ }^{14}$ DANA-WH, ${ }^{15}$ archaeology.org, ${ }^{16}$ and $\operatorname{archNet} .{ }^{17}$ These Web portals provide helpful aids for locating links on archaeological topics. Moreover, some individual scholars maintain good Web sites for the purpose of sharing data, research ideas, and other important information.

Basically, online databases represent three major data dissemination formats: those that are searchable through queries, those that are presented as a series of downloadable files, and those that can be used in both ways. Susan Jones spent time comparing the first two types of databases and pinpointing the advantages and disadvantages of each type. According to her findings, it is hard to tell which type is better than the other: 'The "best" presentation method is dependent upon the goals, stability of the data, and resources of the project. ${ }^{18}$ No matter how an online database is organized, it is true that the electronic preservation and dissemination of archaeological data have been a ubiquitous practice within the research community. Now, let us turn to the electronic publication of research results.

\section{Electronic Journals Keep Coming Up}

The first electronic journal for archaeology was Internet Archaeology, initiated in $1996 .{ }^{19}$ It has published articles of a high academic quality, covering topics from archaeological excavations to GIS surveys. A wide array of multimedia techniques is used to present color images, Virtual Reality Modeling Language (VRML), Quick-Time Virtual Reality models, and the like. Within a short time, Internet Archaeology has received broad recognition from scholars. As of 2002, it had been used by more than 27,000 individuals from more than 120 countries, symbolizing great success.

About two years later, another electronic journal of archaeology - Mediterranean Prehistory Online was created. This journal originated from the Early Prehistoric Migration project and soon expanded to cover studies in all aspects of Mediterranean prehistory. ${ }^{20}$ It then set further expansion plans to broaden 
the scope of articles in the journal to include a chronological range from the Lower Paleolithic to the dawn of Classical civilization in the Mediterranean Basin. Keeping high academic standards in mind, this journal strives to take advantage of new digital technology and make it accessible to all researchers. Several other e-journals, such as the Journal of Social Archaeology ${ }^{21}$ and the American Journal of Archaeology, ${ }^{22}$ have also been added to the list. It is worth noting that some of these electronic journals have adopted a peer review process to ensure the quality of their publications, but without slowing down their publication speed. As a matter of fact, the time within which articles become available to the public in most electronic journals can be measured in weeks rather than in months, as was previously the case.

In addition to the peer-reviewed journals, some professional associations and research organizations have started to post their newsletters online; an example is the CSA Newsletter. ${ }^{23}$ Research news, activities, and informal articles can now be shared faster. If these two types of online publications have served the needs of archaeological research in slightly different ways, we will find that a considerable number of electronic publications in archaeology has adopted a very dissimilar approach: one with the public in mind. Or, at least, they are not designed specifically for archaeologists. Selected data are interpreted to favor lay readers for the understanding of particular histories or cultures. Such efforts consist mainly of the practices described below.

\section{Cultural Heritage/Museum Informatics Has a Non-research Emphasis}

The term 'cultural heritage informatics' refers to research that aims to preserve and interpret events and figures in history. Archaeological evidences are regarded as part of cultural heritage, and thus part of the informatics research. In particular, because archaeological discoveries constitute the main part of museum collections, a sub-area of cultural heritage informatics - museum informatics - has explored electronic techniques to bring archaeological collections to public attention. The most recent practice of museum informatics includes using the Web as the vehicle for online exhibits.

Museum informatics has benefited from the founding of the International Conference on Hypermedia and Interactivity in Museums (ICHIM) in 1991. ICHIM was initiated with the intention of promoting the potential of interactive multimedia in museum programs. ${ }^{24}$ Through its biannual meetings, researchers in cultural/ museum informatics are brought together to exchange ideas and create a presence on the Web for their museums.

Major museums have since established a system of digital exhibits. These exhibits are mostly organized under selected topics, using the museums' own collections. Keeping pace with advances in information technologies, the exhibits have become more interactive and multimedia oriented. Visualization has been greatly enhanced, and flexibility to serve different audiences has been increased. Many people find visiting museums only a click away.

Recently, online museums have been developed in two major directions: one that allows art collections to be digitized and displayed on the Internet and one that combines archives with museum collections to describe historical events. The former effort is symbolized by the work of the Art Museum Image Consortium (AMICO), a not-for-profit organization of institutions holding collections of art that collaborate to enable educational use of museum multimedia. ${ }^{25}$ Arts, textiles, and other visual collections are moved to the Web for public access.

At the same time, digital projects involving museum collections and archives are encouraged and supported by the Institute of Museum and Library Services (IMLS) under its National Leadership Grant Program in the United States. ${ }^{26}$ The Colorado Digitization Program is one project that has successfully carried out collaboration among libraries, museums, historical societies, and archives and has created good practices. ${ }^{27}$ Museums in the Online Archive of California is another successful example of such 
efforts. ${ }^{28}$ Similar digital collections can be found on many museums' Web sites, with or without direct support from IMLS.

However, such digital efforts are not really designed for archaeological data sharing. First, digital collections on museums' Web sites are selected for specific exhibition subjects. Like traditional exhibits, they are designed to enhance public understanding of chosen topics, not to facilitate research. Second, the restricted online collections focus primarily on arts and related archival materials. Archaeological discoveries such as potteries, lithic tools, and bronze wares are relatively rare in these presentations. Finally, online collections are not presented in systematic ways. For scientific research, an item may become more informative only when it is associated with other items in an assemblage.

In fact, it is the purpose of most digital museum designs to facilitate easy online visiting for a general audience. Scholarly communication has not been taken into serious consideration in most existing programs. Museums may have found difficulties in presenting their collections on their Web sites; there may be restrictions in terms of financial, technical, and management concerns for individual museums. Difficulties may also come from varied strategies of collection organizations between museums, such as different ways of cataloguing items and implementing metadata.

\section{What are the challenges and opportunities?}

\section{Standards Ensure Efficient Communication}

There are increasing concerns about the exercise of standards in electronic publishing. Standards may apply to the preparation, presentation, or preservation of archaeological data. It is understandable that standards can facilitate scholarly communication. In fact, however, many aspects of current practices lack standards.

Data preparation is typically done by archaeologists through a well-established process of items curation. Preparing data for the Web has brought up new issues in this process in terms of technical and personnel arrangements. New technical tricks of curation have been added in order to satisfy the requirements of online database structure. A result is that some non-archaeologists take part in the process. Because they are less concerned about archaeological research and have limited knowledge of archaeological curation, their participation has inexorably raised questions as to the maintenance of standards. To enhance standards, it may be better to encourage more archaeologists to contribute to related work, and train them in technical skills, than to train others in archaeological specifics.

Data presentation here refers to methods that bring archaeological data to display on the Web. For some years, the diversity of the information technologies has made the task of creating common standards difficult. Various programming schemata have been used to assist in electronic data preservation and presentation. These different schemata have created dialects, making information organization a confusing situation. Scarce resources have not been efficiently used.

In order to improve standards in online publishing in archaeology, several initiatives have been developed. For example, both Spectrum and Categories for the Description Works of Art (CDWA) are intended to be metadata standards for the description of museum collections, and the Visual Resources Association (VRA) core is the metadata schema that handles visual objects specifically, including archaeological materials. Authority control also constitutes an important part of the efforts to enhance standards. The Getty Vocabulary is one of the best-known subject/name authority files in the organization of archaeological material culture. ${ }^{29}$ 
Recently, Extensible Markup Language (XML) has demonstrated its strength as a standard for working with online data presenta-tion. ${ }^{30}$ It also enables scholars to create archaeological data in formats suitable for digital preservation. Designed to be both machine interpretable and human readable, XML not only provides an easy way to describe data but also allows metadata harvesting to ensure cross-domain information flow. Some initiatives, such as HEIRPORT in Britain and XSTAR in the United States, have taken advantage of XML technologies. In Norway, the Museusprosjektet has successfully explored XML capabilities in handling a longrunning digitization project.

From the user's perspective, how online archaeological data are presented determines how those data can be used. Both downloadable and searchable presentations require extensive labor. Recently, Harrison Eiteljorg II has proposed a 'finding-aid' idea. ${ }^{31}$ Obviously, this thought was inspired by archival management in special collections. It could be a viable presentation method allowing scholars to become aware of the existence of wider resources without requiring extensive data preparation. In the future, more data-presentation techniques will be discovered to meet the needs of diverse research projects.

\section{Everything Requires Money}

Financial constraints have greatly limited the ability of archaeologists and information professionals to explore new channels of online publishing. Even some existing projects may face problems in maintenance because of the shortage of money. The ADAP is such an example.

As a core project of the CSA, the ADAP found no way to support its archives financially after several years of operation. As a result, it recently ceased offering its services. In response to the demise of the project, the CSA director has made some suggestions for the efforts of future digital archives. In what he calls the business model, he proposes several improvements based on his experience in the ADAP. Not surprisingly, financial capability is one of the most important recommendations. In fact, he advises a depositor-pay model: 'every project that produces data for deposit will need to find funds to pay for depositing the data. ${ }^{32}$ This is a very unconvincing position because there is no motivation for them to pay.

What would lead data depositors to feel they should pay for others to use their processed data? On the other hand, a pay-to-read model has been used by some electronic journals. After a period of five years of free access to its content, Internet Archaeology began to charge for individual subscriptions in December 2001. In answering critics, the journal's editor notes the high costs of producing the publication. These costs may include expenses in file preservation, editing, and peer review as well as computer hardware and software maintenance. 'It is about time the community recognized that epublication does not come for free. ${ }^{133}$

The availability of electronic journals in other academic fields shows that it is possible for e-publication to be free of charge to readers. ${ }^{34}$ Even in archaeology, some other electronic journals, such as the Journal of Social Archaeology, do not yet charge for access. Nevertheless, it is true that creating and maintaining online archaeological databases does add extra costs. Extensive curation of raw data is necessary for electronic publishing of archaeological data. It may take months, if not years, for archaeologists to complete collection curation of one site. All these jobs require money. Unfortunately, according to Eiteljorg's observation, 'I am aware of no archival plan in the U.S. that has found a funding system that could support an on-going archival storage program for digital archaeological data. ${ }^{135}$ What, then, are the solutions?

The author would argue that two major directions need to be explored in the development of electronic publishing in archaeology. First, it is worth making further efforts to seek reliable funding possibilities. This sounds like a question answering a question. But people are becoming more and more aware of the potential and importance of digital technology, so more funding agencies have offered support for digital 
initiatives. In the United States, for example, the National Science Foundation has recently sponsored numerous repository projects, both institutional and disciplinary.

Second, it is time to seek alternatives for electronic publishing. Online databases have proven to be excellent in disseminating archaeological data; but they are not the only solution. A dilemma is already obvious: How many individual research organizations or excavation projects, apart from those that are well funded, can afford to establish such a database? We can probably do something else to help facilitate archaeological research.

\section{E-Print Repository Is among the Alternatives}

The e-print concept has developed into popular disciplinary and institutional repositories since the early 1990s. Although a variety of e-print applications is currently in use, these applications share many similar characteristics. First, they are all free for download, with the source code open for own customization. Second, they are easy to configure and maintain. Third, they can accommodate various file formats. And finally, they support metadata harvesting to broaden searchability.

Given these characteristics, the e-print repository is clearly a good alternative to current electronic publications in archaeology. It can save tremendous time, money, and energy for individual scholars and research organizations/projects to build and maintain their own Web sites and online databases. The repository can serve as a centralized platform to contain data from any source of excavations. It is now up to archaeologists, rather than information professionals, to decide on what to upload into the repository. Data can be saved in different formats, according to the convenience of resource creators. For example, data on spreadsheets and Microsoft Access tables are still searchable and downloadable.

Maintaining an e-print repository is relatively inexpensive, as is shown by the practices of existing repositories in other academic fields. The business models of presently successful repositories have shown great viability for this type of digital program. For example, an information and library science repository, E-LIS, has adopted a volunteer management style that has greatly reduced operation costs but provided efficient and effective management. ${ }^{36}$ Financial concerns about supporting electronic publishing are minimal here.

A great deal of flexibility is allowed within repository content. Not only can scientific data be saved into an e-print database but research results can also be accommodated. The existing repositories have encouraged the uploading of pre-prints, work before publication, and post-prints, work after publication, as long as copyright issues are properly handled. From this point of view, e-print repository is like an online inventory controlled by its contributors, who are mostly scholars.

Recently, several e-print repositories have been created to support archaeological research. Stevan Harnad proposed to create an archaeology sector in his CogPrints repository (for cognitive sciences) ${ }^{37}$ However, because no significant efforts have been made to attract the attention of scholars, few archaeologists are aware of its existence. Another repository is the Journal of Intercultural and Interdisciplinary Archaeology Disciplinary Repository (JIIA) ${ }^{38}$ Like CogPrints, JIIA has not been successful in gaining the acceptance of the research community. The primary reason is that it was launched in Italy, with Italian as the main language of operation. All other repositories that claim to be for archaeology are only a category subordinate to a broad subject, such as social sciences, or to an institutional repository with an affiliated archaeology program.

Open access is the spirit of e-print repository. ${ }^{39}$ Neither contributors nor users pay for services. Any resource will become available immediately after it has been uploaded to the repository database and reviewed by the manager(s). It is necessary to mention that, because of the lack of a peer-review process, 
users will need to make their own judgements about the quality of the materials in a repository. Yet to relax control over an e-print repository is by no means to lower the value of such a repository as an innovative means of electronic publishing for archaeology.

\section{Conclusion}

Electronic publishing has demonstrated its potential to support archaeological research. Archaeologists and information professionals have worked together to explore various ways to digitally preserve and disseminate archaeological data. Numerous projects have been launched to build online databases and exhibits. These endeavors have successfully promoted scholarly communication in the research community.

Yet development problems do exist: financial constraints have threatened the ongoing practices of some digital projects, and standards have been lacking in the operation of certain online resources. Although recommendations have been made by scholars to solve these problems, it is still doubtful whether any of the proposals is viable. An evaluation of the advances in digital technologies makes clear that e-print repositories may become a useful participant in electronic publishing efforts in archaeology. The management models of existing e-print repositories encourage scholars' contributions and are cost efficient. With proper management, e-print repositories will be able not only to handle archaeological data sharing but also to facilitate the exchange of research ideas and results.

Like other academic disciplines, archaeology is eager for innovative approaches of information exchange. It is the task of scholars to keep abreast of the development of modern technology. In particular, information professionals should become more enthusiastic about helping archaeologists build new systems of scholarly communication.

\section{Notes}

1. Ibironke Lawal, 'Scholarly Communication: The Use and Non-use of E-Print Archives for the Dissemination of Scientific Information,' Issues in Science and Technology Librarianship 36 (Fall 2002), available at: http://www.istl.org/02-fall/article3.html

2. Brian M. Fagan, Archaeology: A Brief Introduction, 6th ed. (New York: Longman 1997)

3. American Anthropological Association (AAA), AAA Guide (Washington, DC: AAA 2005)

4. William Kilbride, 'Digital Preservation Meets Electronic Publishing: Towards an Integrated Resource,' CSA Newsletter 14, 3 (Winter 2002), available at http://csanet.org/newsletter/winter02/nlw0203.html

5. Harrison Eiteljorg II, 'Archiving Archaeological Data: Is There a Viable Business Model for a US Repository?' CSA Newsletter 17, 3 (Winter 2005), available at http://csanet.org/newsletter/winter05/nlw0501.html

6. Archaeological Data Archive project, http://csanet.org/newsletter/nov94/nl119403.html; 'A Database about Databases,' CSA Newsletter 7, 2 (August 1994), available at http://csanet.org/newsletter/aug94/n1089408.html

7. Eiteljorg, 'Archiving Archaeological Data'

8. 'Archaeological Data Archive Pilot Project,' CSA Newsletter 14, 2 (Fall 2001), available at http://csanet.org/newsletter/fall01/nlf0101.html

9. Jon Kenny and William Kilbride, 'Networked Access to Digital Archaeological Archives in the European Area,' CSA Newsletter 15, 2 (Fall 2002), available at: http://csanet.org/newsletter/fall02/nlf0202.html 10. Archaeological Records of Europe - Networked Access (ARENA), http://ads.ahds.ac.uk/arena; Jon Kenny and William Kilbride, 'Europe's Digital Inheritance: ARENA Archives Launched,' CSA Newsletter 16, 1 (Spring 2003), available at http://csanet.org/newsletter/spring03/nls0302.html

11. Kilbride, 'Digital Preservation' 
12. Digital Archaeological Archive of Comparative Slavery (DAACS), http://www.daacs.org

13. The Danebury Excavations Digital Archive,

http://ads.ahds.ac.uk/catalogue/projArch/danebury_var_2003/index.cfm

14. Archaeology from about.com, http://archaeology.about.com; see also C. Susan Jones, 'Access to

Archaeological Resources on the Web,' CSA Newsletter 17, 3 (Winter 2005), available at

http://csanet.org/newsletter/winter05/nlw0504.html

15. Digital Archive Network for Anthropology and World Heritage (DANA-WH), http://www.danawh.net/

16. Archaeology, http://www.archaeology.org; see also Jones, 'Access to Archaeological Resources.'

17. ArchNet Home Page, http://archnet.asu.edu/

18. C. Susan Jones, 'Archaeological Data Preservation Formats on the Web,' CSA Newsletter 17, 2 (Fall

2004), available at $\mathrm{http}: / /$ csanet.org/newsletter/fall04/nlf0402.html

19. Julian Richards, 'Internet Archaeology and the Myth of Free Publication,' Learned Publishing 13, 3

(July 2002): 233-4

20. Dirk Brandherm, 'Scholarly Online Publishing in Archaeology: The Price of Progress,' Mediterranean

Prehistory Online (2 August 2000), available at http://www.ruhr-uni-

bochum.de/ufg/Personal/Dr_D_Brandherm/Brandherm01.pdf

21. Journal of Social Archaeology, http://jsa.sagepub.com/

22. American Journal of Archaeology, http://www.ajaonline.org/

23. CSA Newsletter, http://csanet.org/newsletter/

24. Archimuse Archives and Museum Informatics, http://www.archimuse.com/

25. Art Museum Image Consortium (AMICO), http://www.amico.org/; David Bearman, Kelly Richmond, and Jennifer Trant, 'Open Concepts: Museum Digital Documentation for Education through the AMICO

Library,' International Cultural Heritage Meeting, Milan, Italy, 6 September 2001, available at

http://www.amico.org/docs/papers/2001/trant.ichim01.pdf

26. Timothy W. Cole and Sarah L. Shreeves, 'The IMLS NLG Program: Fostering Collaboration,' Library Hi Tech 22, 3 (September 2004): 246-8; Joyce Ray, 'Connecting People and Resources: Digital Programs at the Institute of Museum and Library Services,' Library Hi Tech 22, 3 (September 2004): 249-53

27. Brenda Bailey-Hainer and Richard Urban, 'The Colorado Digitization Program: A Collaboration

Success Story,' Library Hi Tech 22, 3 (September 2004): 254-62

28. Robin Chandler, 'Museums in the Online Archive of California (MOAC): Building Digital Collections across Libraries and Museums,' First Monday 7, 5 (May 2002), available at

http://www.firstmonday.org/issues/issue 7 5/chandler/index.html; Online Archive of California (OAC), http://www.oac.cdlib.org/

29. The Getty Vocabularies, http://www.getty.edu/research/conducting research/vocabularies/

30. William Kilbride, 'Past, Present and Future: XML, Archaeology and Digital Preservation,' CSA

Newsletter 17, 3 (Winter 2005), available at http://csanet.org/newsletter/winter05/nlw0502.html

31. Harrison Eiteljorg II, 'A Wider Vision of an Archaeological Data Archive,' CSA Newsletter 17, 3

(Winter 2005), available at http://csanet.org/newsletter/winter05/nlw0503.html

32. Eiteljorg, 'Archiving Archaeological Data'

33. Richards, 'Internet Archaeology'

34. For example, in the field of information and library science, D-Lib Magazine, http://www.dlib.org, is free to readers.

35. Eiteljorg, 'Archiving Archaeological Data'

36. E-LIS: E-prints in Library and Information Science, http://eprints.rclis.org/

37. See Stevan Harnad, 'Eprints for Archaeology?' American Scientist Open Access Forum (29 November 2001), http://www.ecs.soton.ac.uk/ harnad/Hypermail/Amsci/1685.html

38. Journal of Intercultural and Interdisciplinary Archaeology and Archaeological Disciplinary

Repository, http://www.jiia.it/

39. See Peter Suber, 'Open Access Overview' (10 March 2006),

http://www.earlham.edu/ peters/fos/overview.htm 